\title{
Seasonal Change of Gas/Particle Partitioning of Atmospheric Dioxins
}

\author{
Hideo Oka, ${ }^{*}, a, b$ Hitoshi Kakimoto ${ }^{a}{ }$ Yoshiaki Miyata, ${ }^{a}$ Yumiko Yonezawa, ${ }^{a}$ Akiko Niikawa, ${ }^{a}$ \\ Hirohisa Kyudoh, ${ }^{a}$ Ning Tang, ${ }^{b}$ Akira Toriba, ${ }^{b}$ Ryoichi Kizu, ${ }^{b, 1}$ and Kazuichi Hayakawa ${ }^{b}$
}

${ }^{a}$ Ishikawa Prefectural Institute of Public Health and Environmental Science, 1-11 Taiyogaoka, Kanazawa 920-1154, Japan and

${ }^{b}$ Graduate School of Natural Science and Technology, Kanazawa University, Kakuma-machi, Kanazawa 920-1192, Japan

(Received October 3, 2005; Accepted October 11, 2005; Published online October 14, 2005)

\begin{abstract}
Air samples were collected at suburban Kanazawa and concentrations of dioxins in both gaseous and particulate phases were determined separately. The concentrations of the gaseous phase of dioxins increased with increasing temperature. Co-planar polychlorinated biphenyls (co-PCBs), whose vapor pressures are higher than those of polychlorinated dibenzo-p-dioxins (PCDDs) and dibenzofurans (PCDFs), were mainly in the gaseous phase samples in all the seasons. The gaseous phase ratios [gaseous phase/(gaseous phase + particulate phase)] of tetrachloro dibenzop-dioxins and dibenzofurans (TeCDD/DFs) were high regardless of the temperature. However, the gaseous phase ratios of penta-hepta CDD/DFs varied widely depending on the temperature. Gas/particle partitioning of atmospheric dioxins depended on not only the number of chlorine-substitutions but also the positions of the chlorinesubstitutions. The position of chlorine-substitution in an isomer affects the isomer's molecular polarity. Dioxin isomers with higher molecular polarity, which have shorter retention times on the selected ion monitoring (SIM) chromatograms of their homologues, tended to be distributed unevenly in the gaseous phase. In addition, the differences in the gaseous phase ratios between the isomers with higher molecular polarity and those with lower molecular polarity increased with decreasing temperature.
\end{abstract}

Key words — atmospheric dioxin, gas/particle partitioning, polychlorinated dibenzo-p-dioxin, polychlorinated dibenzofuran, co-planar polychlorinated biphenyl, isomer

\section{INTRODUCTION}

The composition of atmospheric dioxins is affected by both dioxins in the exhaust gas from combustion processes and soil dioxins that are blown into the air. ${ }^{1,2)}$ In general, several specific dioxin isomers, which are indicators of the herbicides chloronitrophen (CNP) and pentachlorophenol (PCP), are still abundant in present-day soil samples. ${ }^{3-5)}$ These two herbicides were once widely used in Japanese rice fields and contained specific dioxin isomers as impurities. ${ }^{3,6)}$ We previously showed that the concentration ratios of the specific isomers to their homologues of the air samples sig-

${ }^{1}$ Present address: Faculty of Pharmaceutical Sciences, Doshisha Women's College of Liberal Arts, Kodo, Kyotanabe, Kyoto 6100395, Japan

*To whom correspondence should be addressed: Ishikawa Prefectural Institute of Public Health and Environmental Science, 1-11 Taiyogaoka, Kanazawa 920-1154, Japan. Tel.: +8176-229-2011; Fax: +81-76-229-1688; E-mail: okahideo@pref. ishikawa.jp nificantly decreased in winter, probably as a result of suppression of wind-blown soil by the snow cover or by a soil surface wetted with winter rain.7)

To examine the toxicity of atmospheric dioxins, we usually determined the total (gaseous phase + particulate phase) concentrations. Only the gaseous phase dioxins are believed to be degraded, while the particulate phase dioxins are easily blown far from their sources in the air. Thus, to evaluate the risk of human exposure to atmospheric dioxins through inhalation, it is necessary to understand the detailed behavior of dioxins in the atmosphere. In the present study, we determined the concentrations of both gaseous phase and particulate (particle-bound) phase of dioxins separately in different seasons (from early spring to winter).

Previous studies of gas/particle partitioning of dioxins were usually done at the homologue level. ${ }^{8,9)}$ In the present study, however, we focus on the gas/particle partitioning of all the isomers of each homologue. Then, by using the results, we discuss the relationship between the gas/particle partition- 
ing of each of the isomers and the retention times of the isomers on the selected ion monitoring (SIM) chromatograms.

\section{MATERIALS AND METHODS}

Sampling — Air samples were collected with a high-volume air sampler (HV-700F; Sibata, Tokyo, Japan) at a flow rate of $100 \mathrm{l} / \mathrm{min}$ on the rooftop of a three-story building at a suburban site (1-11 Taiyogaoka) in Kanazawa, Japan. The sampling site was $6 \mathrm{~km}$ southeast of the downtown area of Kanazawa and on a hill which rose about $100 \mathrm{~m}$ above sea level. The sampling site was surrounded by a newly developed residential area and farming area (rice fields and orchards). No major emission source of dioxins was near the sampling site.

The air was sampled from March 2003 to January 2004 intermittently and each sampling period was a week or two weeks. Thus, we obtained 17 air samples. The particulate phase of dioxins was collected on quartz fiber filters (QFF), while the gaseous phase of dioxins was adsorbed in two polyurethane foam (PUF) plugs attached to the high-volume air samplers.

\section{Pretreatment Procedure —— The PUF and QFF} of each air sample were Soxhlet extracted for $20 \mathrm{hr}$ in acetone and in toluene, respectively. In the present study, gas phase samples and particulate phase samples were pretreated separately according to procedures published by the Ministry of Environment, Japan with minor modifications. The detailed processes of sample pretreatment were previously described.7)

GC/MS Analysis After pretreating the samples, $1 \mu \mathrm{l}$ of the final solutions was injected into a high resolution GC/MS (HP-6890; Hewlett Packard, Wilmington, DE, U.S.A. + MS-700D; JEOL, Tokyo, Japan). Polychlorinated dibenzo- $p$ dioxins and dibenzofurans (PCDD/DFs) and co-planar polychlorinated biphenyls (co-PCBs) were measured by the SIM method as described previously. ${ }^{7)}$ Tetrachloro dibenzo- $p$-dioxins and dibenzofurans (TeCDD/DFs), pentachloro dibenzo-p-dioxins and dibenzofurans (PeCDD/DFs) and hexachloro dibenzo-p-dioxins (HxCDD/DFs) (except $1,2,3,7,8,9-\mathrm{HxCDF})$ were analyzed with a fused silica capillary column SP-2331 $(60 \mathrm{~m} \times 0.32 \mathrm{~mm}$ i.d., $0.20 \mu \mathrm{m}$ film thickness; Supelco, Bellefonte, PA, U.S.A.). Heptachloro dibenzo-p-dioxins and dibenzofurans (HpCDD/DFs), octachloro dibenzo- $p$-dioxin and dibenzofuran (OCDD/DF) and $1,2,3,7,8,9-\mathrm{HxCDF}$ were analyzed with a DB-17 capillary column $(30 \mathrm{~m} \times 0.25 \mathrm{~mm}$ i.d., $0.25 \mu \mathrm{m}$ film thickness; Agilent Technologies, Wilmington, DE, U.S.A.). 12 Co-planar PCB isomers were analyzed with a MIGHTY CAP HT-8PCB $(50 \mathrm{~m} \times 0.22 \mathrm{~mm}$ i.d., $0.25 \mu \mathrm{m}$ film thickness; Kanto Kagaku, Tokyo, Japan).

The concentrations of the isomers were calculated using the software package "Diok Ver. 2" (JEOL). We confirmed that the recovery rates of clean-up spikes added to every sample at the beginning of the pretreatment procedure were in the range of 50 to $120 \%$ according to the measurement manual published by the Ministry of Environment, Japan.

\section{RESULTS AND DISCUSSION}

\section{Atmospheric Concentration of Dioxins}

The gaseous phase concentrations of PCDD/DFs and co-PCBs [Fig. 1(a)] increased with increasing temperature [Fig. 1(c)] except in the sampling period starting on 20 August, 2003. However, the concentration of particulate phase dioxins [Fig. 1(b)] was not clearly related to the temperature. Co-PCBs were detected mainly in the gaseous phase samples in all seasons, probably because co-PCB isomers have higher vapor pressures than do $\mathrm{PCDD} / \mathrm{DF}$ isomers. Subcooled liquid vapor pressures $\left(\mathrm{p}_{\mathrm{L}}\right)$ of $\mathrm{PCB}$ isomers are known to be higher than those of PCDF isomers with the same number of chlorine substitutions. ${ }^{10)}$ PCDDs accounted for most of the particulate phase dioxins in all seasons. The toxic equivalent (TEQ) concentration of total atmospheric dioxins was highest $\left(0.036 \mathrm{pg}-\mathrm{TEQ} / \mathrm{m}^{3}\right)$ in the sampling period starting on 1 April, 2003 and lowest $\left(0.0091 \mathrm{pg}-\mathrm{TEQ} / \mathrm{m}^{3}\right)$ in the sampling period starting on 20 August, 2003 (Table 1). The TEQ values were correlated with the real atmospheric concentrations in both gaseous phase and particulate samples.

The real concentrations of the gaseous phase and particulate phases were extremely low in the sampling period starting on 20 August, 2003 (Fig. 1). A local downpour occurred during this period in Kanazawa, with $110 \mathrm{~mm}$ of precipitation within a day. The low atmospheric concentration might have been due to the washing out effect of such a heavy rainfall. A significant decrease in the contribution ratio (\%) of gaseous phase [gas/(gas + particle)] to the TEQ was observed in the sampling period with 
(a)

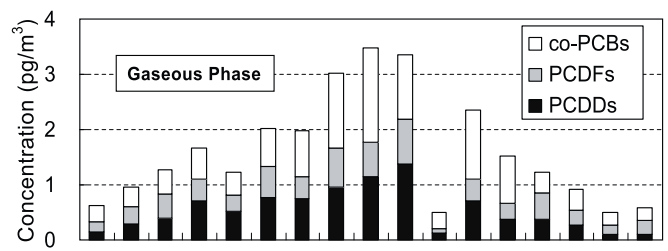

(b)
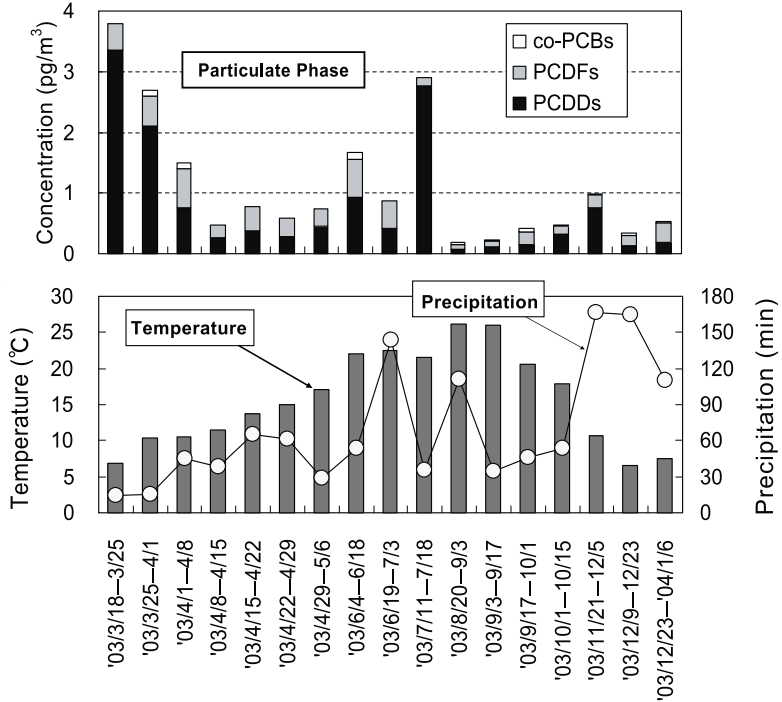

Fig. 1. Atmospheric Concentrations of (a) the Gaseous Phase of Dioxins, (b) the Particulate Phase of Dioxins, and (c) Mean Temperature and Precipitation in the Every Sampling Period

the downpour, while the gaseous phase ratios $(\%)$ of both PCDD/DFs and co-PCBs in the real atmospheric concentration did not decrease so remarkably in this sampling period (Table 1).

The ratios of several isomers that are indicators of CNP, such as 1,3,6,8-tetrachloro dibenzo- $p$-dioxin (1,3,6,8-TeCDD), 1,2,3,6,8-pentachloro dibenzo- $p$ dioxin (1,2,3,6,8-PeCDD) and 2,4,6,8-tetrachloro dibenzofuran $(2,4,6,8-\mathrm{TeCDF})$, to their homologues were smaller in the early spring and winter than in the other seasons (Fig. 2). This result well agreed with our previous study. ${ }^{7)}$ The above ratios of the specific isomers to their homologues in both gaseous phase samples and particulate phase samples similarly varied with season (data not shown in Fig. 2).

\section{Contributions of Toxic Isomers to the TEQ}

The toxicities of dioxins are, in general, expressed by the TEQ, which is the sum total of the product of the concentrations of the toxic isomers and their toxicity equivalent factors (TEFs). We previously reported that the main isomers contributing to the TEQ of the cinder samples were different from the main isomers contributing to the TEQ of the soil samples. ${ }^{7)}$ The former were purely of combustionorigin, while the latter more or less originated from agrochemicals.

Figure 3 shows the yearly averaged contribution ratios of the toxic isomers to the total TEQ in both gaseous phase and particulate phase of atmospheric dioxins. 2,3,4,7,8-Pentachloro dibenzofran $(2,3,4,7,8-\mathrm{PeCDF})$ was the largest contributor (29.9\% for the gaseous phase and $25.5 \%$ for the particulate phase) to the TEQ and was followed by $1,2,3,7,8$-PeCDD (15.2\% for the gaseous phase and $14.1 \%$ for the particulate phase). The above order of toxic isomers and \% ratios of contribution to the TEQ agree well with the results of previous studies. $2,9,11)$

Tetra-penta CDD/DFs made a larger contribution to the TEQ of the gaseous phase samples, while hexa-octa CDD/DFs made a larger contribution to the TEQ of the particulate phase samples. This may be because the isomers with lower chlorine contents tend to be mainly distributed in the gaseous phase while the isomers with higher chlorine contents tend to be mainly distributed in the particulate phase, regardless of the temperature. 3, $3^{\prime}, 4,4^{\prime}, 5$-Pentachloro biphenyl $\left(3,3^{\prime}, 4,4^{\prime}, 5-\mathrm{PeCB}\right)$ was the only co-PCB 
Table 1. The Atmospheric TEQ $\left(\mathrm{pg} / \mathrm{m}^{3}\right.$ ) and the Ratios (\%) of the Gaseous and Particulate Phase of Dioxins, and the Gaseous Phase Ratio (\%) of the Real Atmospheric Concentration

\begin{tabular}{|c|c|c|c|c|c|c|}
\hline \multirow[t]{2}{*}{ Sampling Period } & \multicolumn{3}{|c|}{ TEQ } & \multicolumn{3}{|c|}{$\begin{array}{l}\text { Gaseous Phase Ratio of } \\
\text { the Real Concentration }\end{array}$} \\
\hline & $\begin{array}{c}\text { Gaseous Phase Sample } \\
(\%)\end{array}$ & $\begin{array}{c}\text { Particulate Phase Sample } \\
(\%)\end{array}$ & Total & $\begin{array}{c}\text { PCDD/DFs } \\
(\%)\end{array}$ & $\begin{array}{c}\text { co-PCBs } \\
(\%)\end{array}$ & $\begin{array}{r}\text { Total } \\
(\%)\end{array}$ \\
\hline $2003 / 3 / 18-2003 / 3 / 25$ & $0.0025 \quad(7.9)$ & $0.029(92.1)$ & 0.031 & 8.1 & 75.4 & 13.8 \\
\hline 2003/3/25-2003/4/1 & $0.0023 \quad(9.1)$ & $0.023 \quad(90.9)$ & 0.025 & 18.7 & 81.2 & 26.4 \\
\hline 2003/4/1-2003/4/8 & 0.0078 (21.9) & $0.028 \quad(78.1)$ & 0.036 & 37.5 & 82.4 & 45.9 \\
\hline 2003/4/8-2003/4/15 & $0.0066(45.4)$ & $0.0080(54.6)$ & 0.015 & 69.8 & 92.9 & 76.2 \\
\hline $2003 / 4 / 15-2003 / 4 / 22$ & $0.0032(16.0)$ & $0.017 \quad(84.0)$ & 0.020 & 51.2 & 90.3 & 60.0 \\
\hline 2003/4/22-2003/4/29 & $0.0072(35.2)$ & $0.013 \quad(64.8)$ & 0.021 & 69.1 & 94.2 & 76.0 \\
\hline 2003/4/29-2003/5/6 & $0.0085(40.2)$ & $0.013 \quad(59.8)$ & 0.021 & 60.8 & 93.1 & 71.3 \\
\hline 2003/6/4-2003/6/18 & $0.015 \quad(42.0)$ & $0.020 \quad(58.0)$ & 0.035 & 51.6 & 92.9 & 64.5 \\
\hline 2003/6/19-2003/7/10 & $0.012 \quad(45.3)$ & $0.014 \quad(54.7)$ & 0.026 & 67.0 & 96.9 & 79.0 \\
\hline 2003/7/11-2003/7/18 & $0.019 \quad(64.6)$ & $0.010 \quad(35.4)$ & 0.029 & 42.9 & 97.6 & 53.4 \\
\hline 2003/8/20-2003/9/3 & $0.0034(37.4)$ & $0.0057(62.6)$ & 0.0091 & 56.9 & 88.9 & 71.7 \\
\hline 2003/9/3-2003/9/17 & $0.0086(64.8)$ & $0.0047(35.2)$ & 0.013 & 84.6 & 97.9 & 91.2 \\
\hline 2003/9/17-2003/10/1 & $0.0067(38.8)$ & $0.011 \quad(61.2)$ & 0.017 & 64.7 & 95.0 & 78.7 \\
\hline $2003 / 10 / 1-2003 / 10 / 15$ & $0.0089(63.8)$ & $0.0050(36.2)$ & 0.014 & 65.1 & 97.5 & 72.4 \\
\hline $2003 / 11 / 21-2003 / 12 / 8$ & $0.0057(36.0)$ & $0.010 \quad(64.0)$ & 0.016 & 36.1 & 93.5 & 48.1 \\
\hline 2003/12/9-2003/12/23 & $0.0030(26.1)$ & $0.0084(73.9)$ & 0.011 & 46.5 & 87.9 & 59.6 \\
\hline 2003/12/23-2004/1/6 & $0.0037(27.1)$ & $0.0099(72.9)$ & 0.014 & 40.7 & 87.2 & 52.4 \\
\hline
\end{tabular}

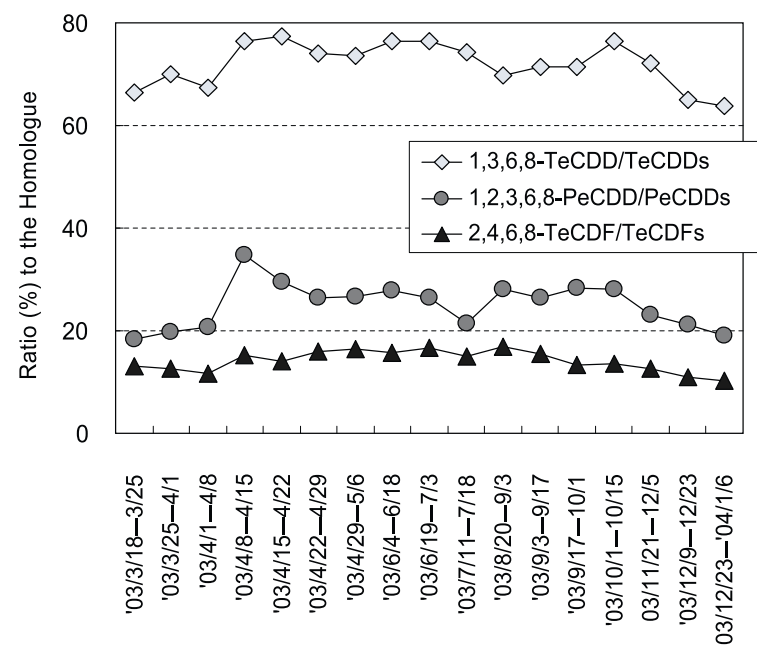

Fig. 2. Seasonal Changes of the Atmospheric Concentration Ratios (\%) of 1,3,6,8-TeCDD, 1,2,3,6,8-PeCDD and 2,4,6,8-TeCDF to their Homologues

isomer that made a significant contribution to the TEQ of the gaseous phase.

\section{Seasonal Change of the Gas/Particle Partitioning of Atmospheric Dioxins}

Figure 4 shows the relationships between the \% ratios of the gaseous phase of $\mathrm{PCDD} / \mathrm{DF}$ and co-
PCB homologues and temperature. The gaseous phase ratios of both TeCDD/DF and TeCB remained high (usually $>70 \%$ ) regardless of the temperature [Fig. 4(a)]. However, the ratios of penta-, hexa- and hepta CDD/DF homologues [Fig. 4(b)-(d), respectively] varied widely (11-89\% for PeCDD/DF, 2$72 \%$ for $\mathrm{HxCDD} / \mathrm{DF}$ and $0-40 \%$ for $\mathrm{HpCDD} / \mathrm{DF}$ ) over the cold and warm season. The gaseous phase ratios of co-PCB homologues were much higher (78$98 \%$ for co-PeCB, 38-95\% for co-HxCB and 13$82 \%$ for co-HpCB) than those of penta-hepta CDD/ DFs with same number of substituted chlorines. The gas/particle partitioning of PCDDs was not significantly different from that of PCDFs in the present study (Fig. 4).

The gas/particle partitioning was affected by not only the above-mentioned number of chlorine substitutions but also the positions of chlorine substitutions. Among the isomers of tetra-octa CDFs, those with short retention times in the SIM chromatograms (i.e., those with low $\mathrm{T} / \mathrm{T}_{0}$ ratios in Table 2) tended to be mainly distributed in the gaseous phase.

The difference in the retention time on the chromatogram, that is, the difference in the elutability from the GC column, in general, reflects the difference in the molecular polarity between the isomers. ${ }^{10}$ Therefore, the results shown in Table 2 suggest that 


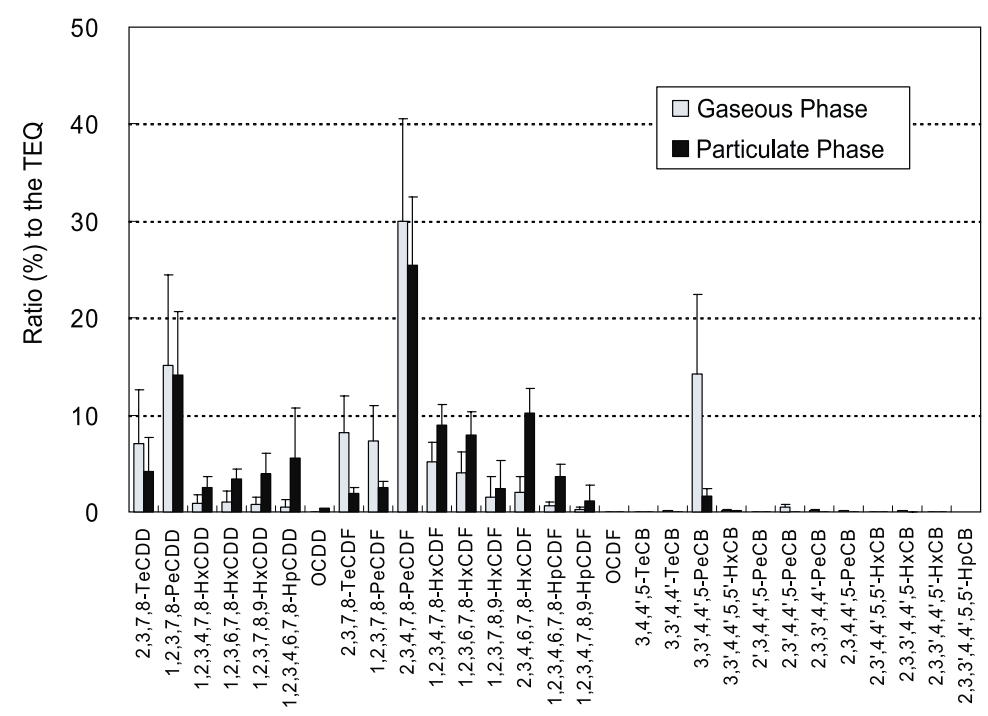

Fig. 3. Contribution Ratios (\%) of Toxic Dioxin Isomers to the TEQ in the Gaseous Phase and the Particulate Phase Samples Each box and bar represent mean and S.D., respectively $(n=17)$.

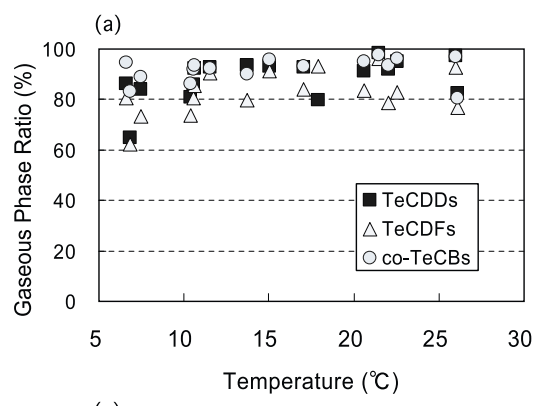

(c)

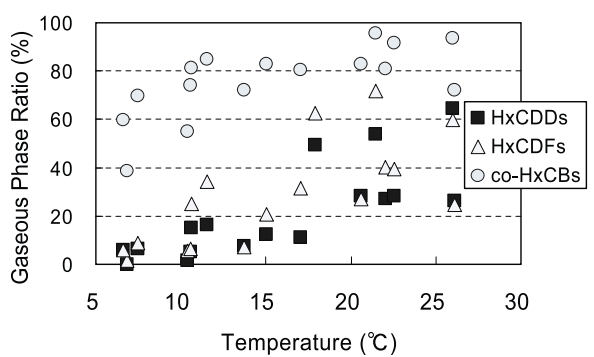

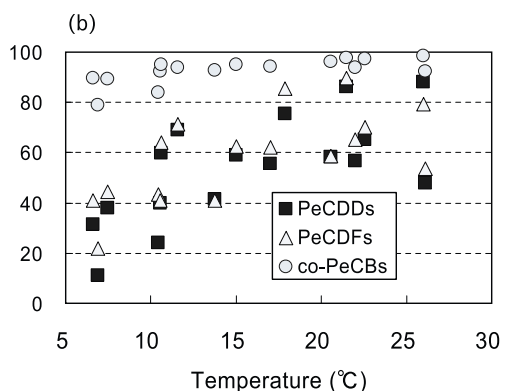

(d)

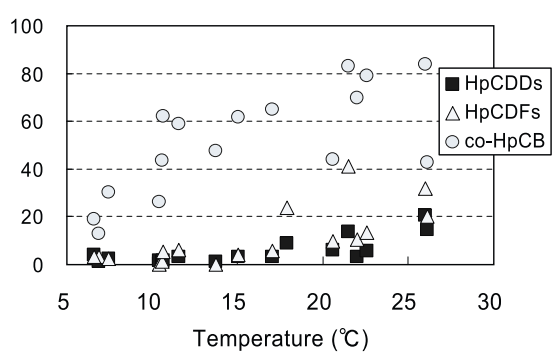

Fig. 4. Plots of the Ratio (\%) of the Gaseous Phase of (a) Tetra, (b) Penta, (c) Hexa and (d) Hepta CDD/DFs and co-PCBs Homologues vs. Temperature

the gas/particle partitioning depends on the molecular polarity of the dioxin isomers. The molecular polarity of an isomer is, in turn, known to be related to several parameters, such as its vapor pressure. ${ }^{12-14)}$ The data in Table 2 also show that the gaseous phase ratio of an isomer tends to increase with increasing vapor pressure.

Figure 5 shows the seasonal changes of the gaseous phase ratios of the four main isomers of TeCDFs. 1,3,6,8-TeCDF has the shortest retention time $\left(\mathrm{T} / \mathrm{T}_{0}=1.00\right.$ in Table 2), 2,4,6,8- and 1,2,7,8TeCDF have medium retention times $\left(\mathrm{T} / \mathrm{T}_{0}=1.23\right.$ and 1.28 , respectively) and 2,3,7,8-TeCDF has a relatively long retention time $\left(\mathrm{T} / \mathrm{T}_{0}=1.45\right)$. The difference in the gaseous phase ratios between the isomer with the shorter retention time and the isomers with longer retention times was larger in the early spring (sampling period starting on 18 and 25 March, 2003) and winter (sampling period starting on 23 December, 2003). This phenomenon was remarkable in the 
Table 2. Concentration Ratio (\%) of the Gaseous Phase of All the Isomers of Tetra-Octa CDF Homologues ( $n=17)$, Relative Retention Times and Subcooled Liquid Vapor Pressures of the Isomers

\begin{tabular}{|c|c|c|c|c|}
\hline Homologue & Isomer & $\begin{array}{c}\text { Gaseous Phase Ratio (\%) } \\
\text { mean } \pm \text { S.D. }\end{array}$ & $\mathrm{T} / \mathrm{T}_{0}$ & $-\log \mathrm{P}(\mathrm{Pa})$ \\
\hline \multirow[t]{21}{*}{ TeCDFs } & $1,3,6,8-$ & $88.5 \pm 5.6$ & 1.00 & 2.93 \\
\hline & $1,3,7,8 / 1,3,7,9-$ & $86.0 \pm 8.4$ & 1.08 & 3.29 \\
\hline & $1,3,4,7-$ & $85.5 \pm 8.7$ & 1.10 & 3.07 \\
\hline & $1,4,6,8-$ & $87.5 \pm 8.2$ & 1.11 & 3.16 \\
\hline & $1,2,4,7 / 1,3,6,7-$ & $87.7 \pm 6.5$ & 1.12 & 3.03 \\
\hline & $1,3,4,8-$ & $84.8 \pm 7.9$ & 1.14 & 3.10 \\
\hline & $1,3,4,6 / 1,2,4,8-$ & $87.6 \pm 8.0$ & 1.16 & 3.18 \\
\hline & $1,2,4,6 / 1,2,6,8-$ & $86.4 \pm 7.5$ & 1.18 & 3.17 \\
\hline & $1,4,7,8 / 1,3,6,9 / 1,2,3,7-$ & $85.2 \pm 6.5$ & 1.19 & 3.30 \\
\hline & $1,6,7,8 / 1,2,3,4-$ & $85.2 \pm 8.3$ & 1.22 & 3.30 \\
\hline & $2,4,6,8 / 1,2,3,8 / 1,4,6,7 / 1,2,3,6-$ & $85.4 \pm 8.2$ & 1.23 & 3.24 \\
\hline & $1,3,4,9-$ & $80.1 \pm 26.1$ & 1.27 & 3.52 \\
\hline & $1,2,7,8-$ & $77.1 \pm 12.6$ & 1.28 & 3.45 \\
\hline & $1,2,6,7 / 1,2,7,9-$ & $80.9 \pm 10.8$ & 1.31 & 3.46 \\
\hline & $2,3,6,8-$ & $80.6 \pm 11.4$ & 1.34 & 3.23 \\
\hline & $2,4,6,7-$ & $78.7 \pm 12.4$ & 1.38 & 3.36 \\
\hline & $2,3,7,8-$ & $66.2 \pm 16.4$ & 1.45 & 3.79 \\
\hline & $2,3,4,8-$ & $75.1 \pm 15.7$ & 1.45 & 3.35 \\
\hline & $2,3,4,6-$ & $76.8 \pm 9.4$ & 1.47 & 3.61 \\
\hline & $2,3,6,7-$ & $72.5 \pm 15.8$ & 1.48 & 3.55 \\
\hline & $3,4,6,7-$ & $71.6 \pm 14.1$ & 1.54 & 3.84 \\
\hline \multirow[t]{17}{*}{ PeCDFs } & $1,3,4,6,8-$ & $74.7 \pm 12.1$ & 1.00 & 3.92 \\
\hline & $1,2,4,6,8-$ & $72.4 \pm 15.5$ & 1.02 & 3.96 \\
\hline & $1,3,6,7,8-$ & $66.1 \pm 15.5$ & 1.05 & 4.05 \\
\hline & $1,3,4,7,9-$ & $65.3 \pm 21.0$ & 1.07 & 4.24 \\
\hline & $1,2,3,6,8 / 1,3,4,7,8-$ & $64.9 \pm 15.9$ & 1.08 & 4.05 \\
\hline & $1,2,4,7,8$ & $64.7 \pm 17.4$ & 1.10 & 4.05 \\
\hline & $1,2,4,7,9 / 1,3,4,6,7-$ & $65.6 \pm 18.1$ & 1.12 & 4.24 \\
\hline & $1,2,4,6,7-$ & $64.1 \pm 17.2$ & 1.13 & 3.96 \\
\hline & $1,4,6,7,8 / 1,2,3,4,7-$ & $62.6 \pm 17.9$ & 1.14 & 4.10 \\
\hline & $1,3,4,6,9$ & $66.0 \pm 25.1$ & 1.16 & 4.39 \\
\hline & $1,2,3,4,8 / 1,2,3,7,8-$ & $57.7 \pm 17.7$ & 1.17 & 4.14 \\
\hline & $1,2,3,6,7-$ & $58.6 \pm 17.6$ & 1.20 & 4.09 \\
\hline & $1,2,4,6,9 / 1,2,6,7,8-$ & $55.6 \pm 20.3$ & 1.22 & 4.55 \\
\hline & $2,3,4,6,8-$ & $52.1 \pm 25.7$ & 1.29 & 4.16 \\
\hline & $1,2,4,8,9-$ & $38.6 \pm 27.2$ & 1.33 & 4.86 \\
\hline & $2,3,4,7,8-$ & $40.2 \pm 22.7$ & 1.40 & 4.71 \\
\hline & $2,3,4,6,7-$ & $39.7 \pm 22.5$ & 1.43 & 4.52 \\
\hline \multirow[t]{8}{*}{$\mathrm{HxCDFs}$} & $1,2,3,4,6,8-$ & $34.7 \pm 25.0$ & 1.00 & 4.76 \\
\hline & $1,3,4,6,7,8 / 1,3,4,6,7,9-$ & $33.3 \pm 24.3$ & 1.01 & 5.06 \\
\hline & $1,2,4,6,7,8-$ & $34.1 \pm 24.5$ & 1.02 & 4.87 \\
\hline & $1,2,3,4,7,8 / 1,2,3,4,7,9-$ & $27.5 \pm 20.6$ & 1.08 & 5.23 \\
\hline & $1,2,3,6,7,8$ & $26.5 \pm 22.2$ & 1.09 & 5.23 \\
\hline & $1,2,3,6,7,9$ & $17.5 \pm 23.6$ & 1.12 & 5.31 \\
\hline & $1,2,3,4,6,9 / 1,2,3,6,8,9-$ & $21.2 \pm 19.7$ & 1.17 & 5.47 \\
\hline & $2,3,4,6,7,8$ & $14.2 \pm 15.6$ & 1.34 & 5.12 \\
\hline
\end{tabular}

Relative retention time $\left(\mathrm{T} / \mathrm{T}_{0}\right)$ means the ratio of the retention time of every isomer $(\mathrm{T})$ divided by the retention time of the isomer which eluted earliest among all the isomers $\left(\mathrm{T}_{0}\right)$ of their homologues. The names of all the isomers in this table are in the order of the retention time on their $\mathrm{SIM}$ chromatograms. Values of subccoled liquid vapor pressure at $25^{\circ} \mathrm{C}$; P $(\mathrm{Pa})$ listed in this table were calculated by Govers and Krop (1998) ${ }^{14)}$ and the values of inseparable peaks which include multiple isomers mean the average of subcooled liquid vapor pressures of these isomers. 
Table 2. Continued

\begin{tabular}{llccc}
\hline \hline Homologue & Isomer & $\begin{array}{c}\text { Gaseous Phase Ratio }(\%) \\
\text { mean } \pm \text { S.D. }\end{array}$ & T/T & $-\log \mathrm{P}(\mathrm{Pa})$ \\
\hline HpCDFs & $1,2,3,4,6,7,8-$ & $11.2 \pm 12.7$ & 1.00 & 5.85 \\
& $1,2,3,4,6,7,9-$ & $9.8 \pm 12.7$ & 1.02 & 5.99 \\
& $1,2,3,4,6,8,9-$ & $10.1 \pm 10.9$ & 1.04 & 6.14 \\
& $1,2,3,4,7,8,9-$ & $9.7 \pm 10.3$ & 1.10 & 6.18 \\
OCDF & $1,2,3,4,6,7,8,9-$ & $4.2 \pm 5.3$ & 1.00 & 6.15 \\
\hline
\end{tabular}

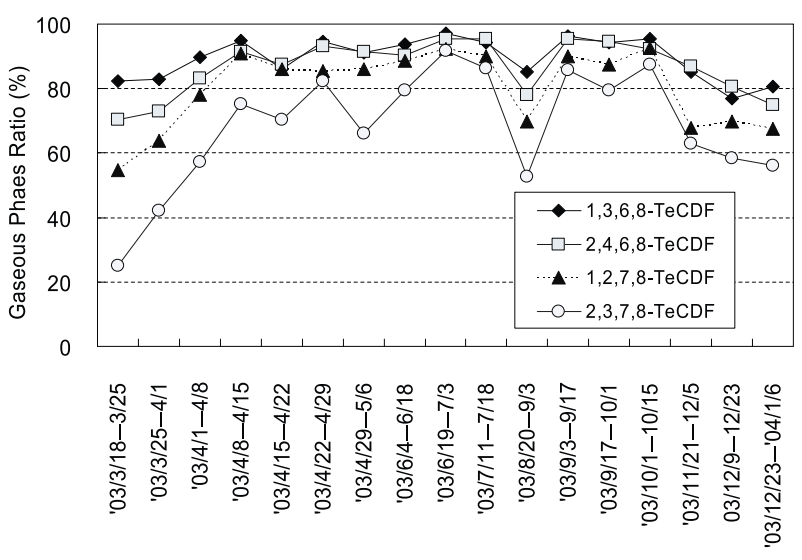

Fig. 5. Seasonal Changes of the Gaseous Phase Ratio (\%) of the Four Main Isomers of TeCDFs

PCDD/DF homologues with lower chlorine contents, such as TeCDD/DFs. On the contrary, the difference in the gaseous phase ratio between isomers tended to be small in the homologues with higher chlorine contents throughout the year. This is because the relative difference in molecular polarity between isomers is smaller for the $\mathrm{PCDD} / \mathrm{DF}$ homologues with higher chlorine contents.

\section{REFERENCES}

1) Baker, J. I. and Hites, R. A. (2000) Is combustion major source of polychlorinated dibenzo- $p$-dioxins and dibenzofurans to the environment? A mass balance investigation. Environ. Sci. Technol., 34, 28792886.

2) Seike, N., Yoshida, M., Matsuda, M., Kawano, M. and Wakimoto, T. (2001) Seasonal change of polychlorinated dibenzo- $p$-dioxins and dibenzofurans in atmosphere. Journal of Environmental Chemistry, 11, 455-465.

3) Seike, N., Ohtani, T., Ueji, M., Takasuga, T. and Tsuzuki, N. (2003) Temporal change of polychlorinated dibenzo- $p$-dioxins, dibenzofurans and dioxin- like polychlorinated biphenyls source in paddy fields. Journal of Environmental Chemistry, 13, 117131.

4) Sakai, M., Kajihara, H., Fukumura, K., Kobayashi, J., Ohizumi, M., Takahashi, Y., Nakadaira, H. and Yamamoto, M. (2002) Time trends and source for dioxins in sediments in a large-scale rice production area, Niigata, Japan. Organohalogen Compounds, 57, 11-14.

5) Masunaga, S., Yao, Y., Ogura, I., Sakurai, T. and Nakanishi, J. (2003) Source and behavior analysis of dioxins based on congener-specific information and their application to Tokyo Bay basin. Chemosphere, 53, 315-324.

6) Masunaga, S., Takasuga, T. and Nakanishi, J. (2001) Dioxin and dioxin-like PCB impurities in some Japanese agrochemical formulations. Chemosphere, $\mathbf{4 4}$, 873-885.

7) Kakimoto, H., Oka, H., Harada, Y., Ushijima, S., Toriba, A., Kizu, R. and Hayakawa, K. (2004) Comparison of compositions of polychlorinated dibenzop-dioxins (PCDDs) and dibenzofurans (PCDFs) in air and soil samples collected in Ishikawa. J. Health Sci., 50, 58-65.

8) Masunaga, S., Yao, Y., Ogura, I. and Sakurai, T. (2001) Source and behavior analysis of dioxins based on composition data. In Proceedings of the 4th international workshop of on risk evaluation and management of chemicals, Institute of Environmental Science and Technology, Yokohama National University, Yokohama, Japan, pp. 39-48.

9) Yoshida, H., Sasaki, Y., Tsukui, T. and Iimura, F. (2002) Vapor-particle partition of atmospheric PCDDs, PCDFs and co-PCBs. Annual report of the Tokyo Metropolitan Research Institute for Environmental Protection 2002, 20-30.

10) Eitzer, B. D. and Hites, R. A. (1988) Vapor pressures of chlorinated dioxins and dibenzofurans. Environ. Sci. Technol., 22, 1362-1364.

11) Lohmann, R., Green, N. J. L. and Jones, K. C. (1999) Atmospheric transport of polychlorinated dibenzo$p$-dioxins and dibenzofurans (PCDD/Fs) in air mass across the United Kingdom and Ireland: Evidence 
of emissions and depletion. Environ. Sci. Technol., 33, 2872-2878.

12) Lohmann, R., Lee, R. G. M., Green, N. J. L. and Jones, K. C. (2000) Gas-particle partitioning of PCDD/Fs in daily air samples. Atmos. Environ., 34, 2529-2537.
13) Kaupp, H. and McLachlan, M. S. (1999) Gas/particle partitioning of PCDD/Fs, PCBs, PCNs and PAHs. Chemosphere, 38, 3411-3421.

14) Govers, H. A. J. and Krop, H. B. (1998) Partition constants of chlorinated dibenzofurans and dibenzop-dioxins. Chemosphere, 37, 2139-2152. 